\title{
Experimental Assessment of Thermal Radiation Behavior Emitted by Solid Porous Material
}

\author{
Nattan Roberto Caetano ${ }^{1}$, Giulio Lorenzini ${ }^{2 *}$, Andressa Rocha Lhamby ${ }^{1}$, Vinicyus Mourão Monteiro Guillet ${ }^{1}$, Marcos \\ Antônio Klunk ${ }^{3}$, Luiz Alberto Oliveira Rocha ${ }^{3}$ \\ ${ }^{1}$ Federal University of Santa Maria, Av. Roraima 1000, 97105-900 Santa Maria, RS, Brazil \\ ${ }^{2}$ Department of Engineering and Architecture, University of Parma, Parco Area delle Scienze, 181/A - 43124 Parma, Italy \\ ${ }^{3}$ University of Vale do Rio dos Sinos, Av. Unisinos 950, 93020-190 São Leopoldo, RS, Brazil
}

Corresponding Author Email: giulio.lorenzini @unipr.it

https://doi.org/10.18280/ijht.380101

Received: 10 December 2019

Accepted: 15 February 2020

\section{Keywords:}

radiant fraction, porous burner, porosity, equivalence relation

\begin{abstract}
Porous media burners have been the focus of many studies due to the advantage in different applications in industry, which exhibit a directional emission of thermal radiation and low emission of pollutants. Indeed, these characteristics yields benefits regarding productivity by an environment friendly process. Thus, this work analyzes the behavior of radiation heat flux emitted by materials of different linear densities and porosities, varying the rate of air/fuel mixture and the flame power. In this way, was constructed an experimental setup that consists in a supply system of air/fuel, data acquisition, burner support for the radiation sensor, and the radiometer. This structure enables the displacement from $0^{\circ} \mathrm{C}$ to $90^{\circ} \mathrm{C}$ allowing the analysis of radiation in the area of a semisphere. The results shown that the silicon carbide has higher radiation efficiency than zirconia, due the higher thermal conductivity and emissivity. However, the silicon carbide degraded in one of the measurements. The $\mathrm{ZrO}_{2}$ media has proved challenging to stabilize for equivalence ratios below 0.6. Regarding the porosity, it is concluded that the higher the porosity, the greater the radiation efficiency, the expected result because there is a larger contact area for the reaction to occur within the pores.
\end{abstract}

\section{INTRODUCTION}

Growing energy consumption is a worldwide reality that continues for decades to come [1-4]. According to data from the International Energy Agency, the world demand for energy grows by $56 \%$ by 2040 [5-7]. Carbon emissions, associated with energy generation and consumption worldwide, are expected to increase by $46 \%$ over the next 30 years [ $8-11$ ]. In this scenario, there is a growing need for processes that improve efficiency and reduce the emission of air pollutants [12-16]. These emissions can be predicted by several models $[17,18]$. Porous burners, due to their versatility in radiant power control and high burning efficiency, provide considerable fuel economy, according to Caetano et al. [19]; Zhang et al. [20]; De Lemos [21]; Usman et al. [22]. Besides, according to scientific communities, the insertion of a porous structure makes the mixture air/produce a lower emission of pollutants [23-25]. Thus, this type of equipment has been applied in different industrial segments such as paper, food, and ceramic [26-28]. Among the parameters that affect the operation of porous burners, the material, the porosity, and the equivalence ratio stand out [29-31]. Therefore, understanding their influence on radiant energy emission is of fundamental importance for the optimization of this equipment [32-34].

The present work has as objective the investigation of the thermal radiation behavior by the premixed combustion of fuel natural gas and air, in porous media, concerning the porous material variation and the medium porosity. The study consists in construct an experimental bench to evaluate the radiation behavior in porous burners, evaluate the influence of porous material on the radiation emitted by the burner in various richness of air/fuel mixture, evaluate the influence of medium porosity on the radiant fraction under the same conditions, and compare the results obtained in the study with results found in the literature.

The novelty brought in this study is the behavior of radiation heat flux emitted by different materials, linear densities and porosities in function of the equivalent ratio of combustion.

\section{MATERIALS AND METHODS}

Experimentally investigated the radiation efficiency of methane and air combustion for mixture richness from 0.6 to 0.87 . The burner used was zirconia (with preheating region (RP) of $65 \mathrm{ppi}$, the porosity of $87 \%$ and $3.5 \mathrm{~cm}$ in length flame stabilization region (REC) of $10 \mathrm{ppi}$, the porosity of $84 \%$ and $2.55 \mathrm{~cm}$ height), $51 \mathrm{~mm}$ in diameter and $60.5 \mathrm{~mm}$ in length [35-38].

Radiation-transferred heat was measured using an infrared radiation camera [39-41]. The results show that the radiation efficiency decreases with increasing flame velocity and equivalence ratio [42-44]. The values obtained for the radiation efficiency reach $24 \%$ to $\Phi$ equal to 0.6 and fall to $17 \%$ in $\Phi$ equal to $0.8[45,46]$. For the mixture richness of 0.87 , the radiation efficiency grows back to $19 \%$ [47-49].

Mital et al. [50], analyzed the radiation efficiency in porous cordierite burners (aluminum and magnesium silicate, which may contain iron), with a composition of $(13.78 \% \mathrm{MgO}$, $34.86 \% \mathrm{Al}_{2} \mathrm{O}_{3}, 51.36 \% \mathrm{SiO}_{2}$ ) [51]. The effect of variation on 
pore thickness and pore size of the flame stabilization region was evaluated for the 0.9 mixture richness at powers between 150 and $650 \mathrm{~kW} / \mathrm{m}^{2}$. For a $4 \mathrm{ppcm}$ REC, the change in thickness from 3.2 to $6.5 \mathrm{~mm}$ did not cause significant changes in radiation efficiency - the maximum efficiency was around $30 \%$ for both conditions [52].

However, keeping the REC thickness constant at $3.2 \mathrm{~mm}$ and varying the linear pore density from 4 to $8 \mathrm{ppcm}$, the maximum measured radiation efficiency dropped to $23 \%$ [53]. This difference is due to the smaller optical thickness of the REC of $4 \mathrm{ppcm}$. Larger diameter pores expose deeper parts of the solid matrix to the environment, causing the sufficient surface temperature to rise. The maximum efficiency was found at an intermediate point of the flame stability range (250 $\left.\mathrm{kW} / \mathrm{m}^{2}\right)[54,55]$.

Bouma and De Goey [56], also measured radiation efficiency in porous cordierite burners. These burners have a very small REC, causing stabilization of the flame front near the surface. For a fixed mixing richness of 0.9 , the burner power was varied from 100 to $600 \mathrm{~kW} / \mathrm{m}^{2}$. In this range, radiation efficiency dropped from $33 \%$ to $8 \%$ [57, 58]. Three configurations were evaluated with different layers of silicon carbide and zirconia ceramic foam, operating with premixed methane and air, in a fuel mixture richness range of 0.35 to 0.65 [59]. This operating range achieved a variation in radiation efficiency between $20 \%$ and $35 \%$. In the zirconia burner, the radiation efficiency ranged from $25 \%$ to $50 \%$.

Kaviany [60] presents an experimental analysis of the performance of burners constructed from zirconia/alumina ceramic filters under several operating conditions, evaluating the radiation [61]. The minimum mixture richness in which the flame stabilized was 0.4 . Radiation efficiency ranged from $18 \%$ for higher flame velocities to $28 \%$ for lower flame velocities [62].

For the accomplishment of the study, a bench was built for the development of the experiment. This workbench allows independent control of air and fuel flow rates and measurement of the radiant fraction emitted by the porous media burner [19]. The bench consists of air and fuel supply systems, thermal radiation measurement system, data acquisition system, and the porous media burner. The radiation source is positioned in the center, the device facilitates the precise positioning of the radiometer at different reading angles, ranging from 0 to $180^{\circ}$, as well as in different radial positions, ranging from 50 to $500 \mathrm{~mm} \mathrm{[8]}$.

The device used to measure radiation in the experiment was a MEDTHERM radiometer, with a measurement uncertainty of $3 \%$ [12]. It absorbs the heat flux on the sensor surface and transfers it to an integrated heat sink that stays at a different temperature than the sensor surface. The temperature difference between the two selected points along the sensor heat flow path is a function of the heat being transferred and the absorbed liquid heat flow. At two of these points, the transducers have thermocouples, thus providing a selfgenerated electromagnetic field for the output conductors that is directly proportional to the heat transfer rate [33]

In the experiment, two digital flow controllers of the brand, BRONKHORST, were used. The first model has a maximum operating flow rate of $150 \mathrm{Ls} / \mathrm{min}$, a standard that uses as a reference the pressure of $1 \mathrm{~atm}$ and the temperature of $20^{\circ} \mathrm{C}$ and measurement uncertainty of $0.1 \%$ of a full-scale value. The second has a flow rate of $10 \mathrm{Ls} / \mathrm{min}$ and the same uncertainty. The reading unit is the E-710 digital PS.

For the flow of the air/fuel mixture to occur only at some points of the burner and not on its entire surface, a holedistributing insulating plate is used. Each injection is associated with a flame that may or may not connect with the others depending on the distribution of holes in the insulation board and the burner operating point [19].

The advantage of this configuration is that the air/fuel mixture must be accelerated to pass through the holes in the perforated insulation board. Thus, upon entering the unreacted ceramic, gases have high speeds, making it challenging to return flame. Another advantage is the possibility of optimizing the distribution of the holes in the insulation board to obtain a homogeneous temperature profile throughout the burner, even for high surface area/thickness ratios [12].

The burner is mounted inside a steel casing with an inner diameter of $130 \mathrm{~mm}$ and flanges at both ends to facilitate mounting and dismounting of the equipment, as shown in Figure 1. The gap between the porous element and the steel housing is filled with a layer of alumina-based thermal insulator, resistant up to $1200^{\circ} \mathrm{C}$ [19].

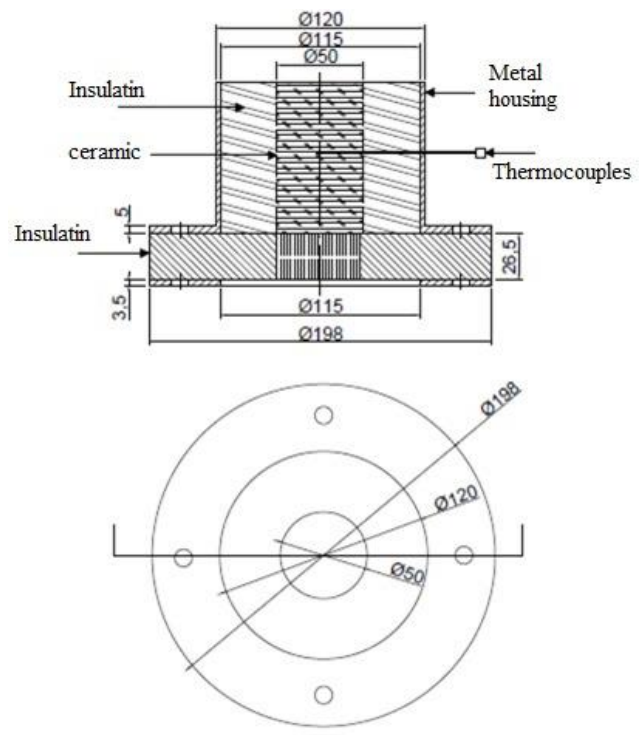

Figure 1. Drawing of the porous burner

The construction of the burner is made from commercial ceramic filters employed in steel casting processes [8]. These filters have a sponge-like structure.

The materials used as porous media are from three different models of commercial filters used separately. The composition of the materials used is zirconia - alumina, $50 \mathrm{~mm}$ in diameter, and $22 \mathrm{~mm}$ thick and 20 ppi, as shown in Figure 2.

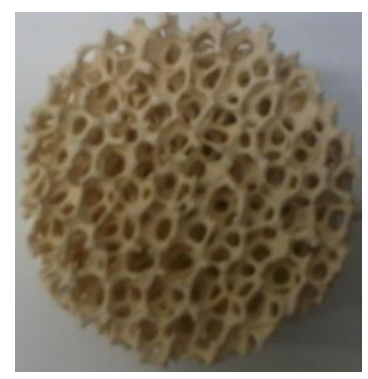

Figure 2. Zirconia Ceramic with 20 ppi of porosity

Porous silicon carbide medium, $50 \mathrm{~mm}$ in diameter, and 22 $\mathrm{mm}$ thick, with two different porosities, one of $10 \mathrm{ppi}$ and one of 20 ppi, can be seen in Figures 3 and 4, respectively. 


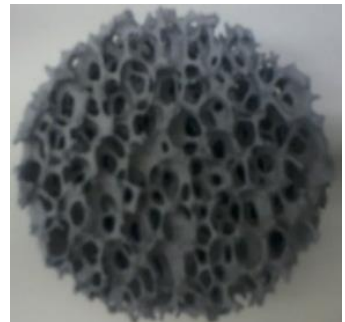

Figure 3. Silicon Carbide Ceramic with 10 ppi of porosity

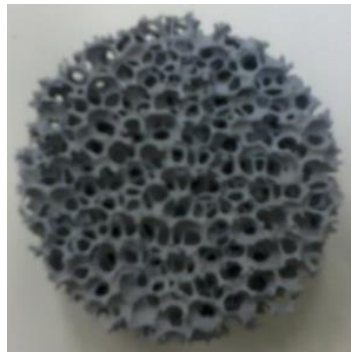

Figure 4. 20 ppi silicon carbide

The methodology used in the experiment was based on the proposal of Hsu et al. [63], which consists of initially finding an air/fuel equivalence ratio and a volumetric gas flow, in which the flame stabilization occurs inside the porous environment. This value is obtained by studying the existing bibliography and preliminary tests performed to verify the functionality of the bench. In this way, an evaluation of the influence of porosity on the radiation emitted by the burner can be obtained $[64,65]$.

The correct burner positioning to the radiometer is of fundamental importance for the validation of the experiment. Only with the precise alignment of the burner top, with the rotating axis of the radiometer holder can measurements be made for a semi-spherical casing. The present experiment used the correction factor in the flow rate of the fuel controller in the value of 0.95 because the controller is calibrated to methane, and in work, the fuel used was natural gas [66].

After flame stabilization, the flow controllers are set to the desired equivalence ratio. The measurement procedure is performed after the thermal equilibrium of the system occurs [67]. Three thermocouples perform thermal monitoring, so this balance is considered when all temperatures do not vary by more than $2^{\circ} \mathrm{C}$ over 10 minutes.

Then the measurement begins by positioning the sensor at a distance of $30 \mathrm{~cm}$ from the burner, taking measurements at four different angles between $0^{\circ}$ (vertical) and $90^{\circ}$ (horizontal). With the correct positioning at the desired angle, the metal barrier, positioned between the burner and the radiometer, is removed, and the radiant heat flow is measured for 100 seconds. After this period, the barrier is positioned and expected until the device is not affected by the previous procedure by monitoring the sensor [68].

The process is repeated for the equivalence ratios of $0.5,0.6$, and 0.7 in the three-burner models. In this way, it is possible to evaluate the radiation behavior in relation to different pore and material densities, for variations of the air/fuel equivalence ratios [69].

\subsection{Measurement uncertainty}

The analysis of experimental uncertainty $(u)$ caused by random errors, which lies in result of the addition of small independent and uncontrollable errors, such as errors of measuring instruments, was performed by applying the method of propagation of independent errors proposed by Kline-McClintock. For the error regarding the measurement of the radiation direction was considered as $u x= \pm 3 \times 10^{-6} \mathrm{~m}$ due the accuracy of the positioners used in the setup. This value is also consistent with the uncertainty in measuring the pixel size during the flame images analysis.

The uncertainty for the average of values obtained in the radiation intensity were considered directly from the statistical results of the electrical signal captured from the sensor, as $u i= \pm 0.5 \%$. An average of 600 measurements for each $\phi$ and for each height above the burner considered in this work were taken. In this way, the value was obtained from the ratio between the largest value of the measured RMS signal amplitude, $200 \mathrm{mV}$, and the average of this signal, $1 \mathrm{mV}$, where the major ratio value in all measurements was considered. Then, the uncertainty related to the radiation emission was considered as $u e= \pm 1.0 \%$, considering the manufacturer information. Thus, the maximum uncertainty in the measurements of radiation heat flux is about $1 \%$ for the results of this work.

An analysis for the equivalence ratio uncertainties, using the flowmeters uncertainties was made, which is yields $5 \%$. The uncertainty of the air flowmeter was $0.2 \mathrm{Sl} / \mathrm{min}$ and for the fuel is $0.15 \mathrm{Sl} / \mathrm{min}$. Thus, the uncertainty in the equivalence ratio is approximately $7 \%$.

\section{RESULTS AND DISCUSSION}

The fuel mass flow $(N G)$ was kept constant at $2.5 \mathrm{Ls} / \mathrm{min}$ to perform the experiments, and consequently, the total energy $\left(S_{r}\right)$ at $1451.5 \mathrm{~W}$ and the air energy was calculated for all cases. The measurements were made primarily for the porous medium composed of 10 ppi silicon carbide and $35.5 \%$ porosity. The results are presented in Table 1:

Table 1. Flow and radiant fraction for different mixing ratios using 10 ppi silicon carbide porous medium

\begin{tabular}{ccc}
\hline $\boldsymbol{\eta}$ & $\boldsymbol{\eta}[\mathbf{\%}]$ & Radiant flux $[\mathbf{W}]$ \\
\hline 0.5 & 15.0 & 210.1 \\
0.6 & 17.4 & 252.4 \\
0.7 & 20.0 & 290.6 \\
\hline
\end{tabular}

Both heat flux and radiant fraction increase with increasing mixing ratio. The same total power value $(1451.5 \mathrm{~W})$ was used in all cases, as the fuel and its flow were the same.

In the second measurement was used the porous medium with silicon carbide composition with 20 ppi and $30.8 \%$ porosity. It was possible to perform only two measurements using this burner configuration due to material decomposition for the equivalence ratio $\varphi=0.7$.

This ceramic filter has a maximum operating temperature of approximately $1300{ }^{\circ} \mathrm{C}$. During data acquisition with temperature reached $1500^{\circ} \mathrm{C}$, or that caused its decomposition. The flux and radiant fraction values for $\varphi=0.7$ were estimated by interpolation of the measured data for the other mixture richness. These data were calculated for comparison with other porosities and materials. This approximation can be considered because the previous solid also presented linear behavior. The results can be seen in Table 2. The variation of 
the radiant fraction was directly proportional to the change of the equivalence ratio.

Table 2. Flux and radiant fraction for different mixing ratios using 20 ppi silicon carbide porous media

\begin{tabular}{ccc}
\hline $\boldsymbol{\varphi}$ & $\boldsymbol{\eta}[\boldsymbol{\%}]$ & Radiant Flux [W] \\
\hline 0.5 & 14.48 & 210.27 \\
0.6 & 16.05 & 232.02 \\
0.7 & 17.87 & 262.63 \\
\hline
\end{tabular}

For the 20 ppi zirconia filter with $29.8 \%$ porosity, the measurements were performed under the same conditions as previous experiments, generating Table 3 . In this composition, no degradation has occurred for any equivalence ratio since its operating temperature is $2300^{\circ} \mathrm{C}$, and in the experiment, the thermocouple monitored an average of $1350^{\circ} \mathrm{C}$. However, there was difficulty in flame stabilization to $\varphi=0.5$.

Table 3. Flux and radiant fraction for different mixing ratios using 20 ppi silicon carbide porous media

\begin{tabular}{ccc}
\hline $\boldsymbol{\varphi}$ & $\boldsymbol{\eta}[\boldsymbol{\%}]$ & Radiant Flux [W] \\
\hline 0.5 & 10.4 & 151.5 \\
0.6 & 13.2 & 191.7 \\
0.7 & 17.4 & 252.5 \\
\hline
\end{tabular}

The radiant fraction for the same equivalence ratio was higher in the lower linear pore density burner, i.e., the higher the porosity, the more radiation is emitted. This phenomenon happens because there is a larger area for heat exchange between the inner pore regions, more irradiated energy, and less heat loss by driving. This behavior is consistent with expected, as verified by Mital et al. [50], and is more evident as it approaches the stoichiometric ratio $(\varphi=1)$. In this condition, there is a more significant heat generation. Consequently, the temperature is higher, which causes more heat loss. Just as the analysis of different porosities was made, one can compare different materials. It is noticed that the silicon carbide material has a higher radiation fraction when compared to the zirconia matrix for the same equivalence ratio. This observation was expected since $\mathrm{SiC}$ has parameters such as higher thermal conductivity and emissivity. However, zirconia burners have the advantage of withstanding higher operating temperatures. Note that the radiant fraction is a relationship between all energy and the measured portion. This value did not exceed $20 \%$ in the experiments, a result considered low compared to the range of 25 to $50 \%$.

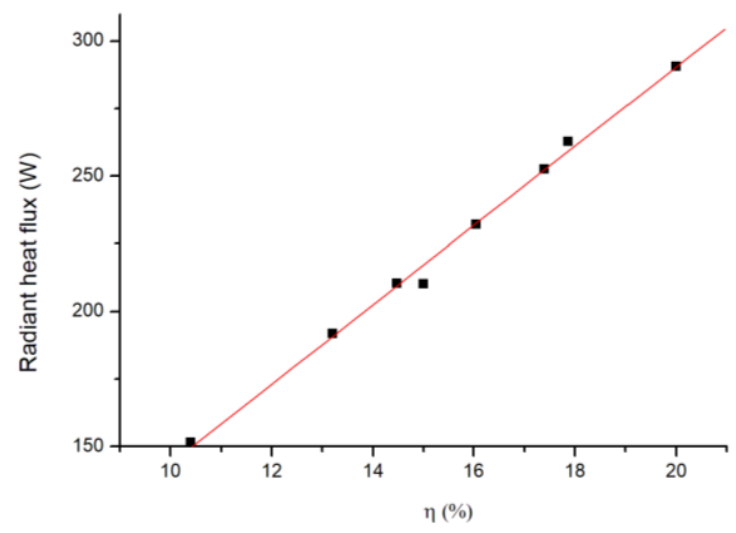

Figure 5. Radiant heat flux $(Q r)$ by mixing ratios for different porosity and materials
Figure 5 shows the graphic of the behavior of the radiant heat flux as a function of different mixing ratios for equivalent ratios, $0.5,0.6$, and 0.7 , for Silicon carbide 10 and 20ppi, and Zirconia 20ppi.

Note that the porosity or material composition does not influence the behavior of the radiation. A linear fit of these data provides a relation of $14.7 \mathrm{~W} / \%$. The standard deviation is $3 \mathrm{~W} / \%$, and the correlation $\mathrm{R}$ is 0.99 . Thus, the variation of the radiation emitted by mixing ratios is independent of the equivalent ratios, porosity, or material of the composition.

Figure 6 shows the graphic of the radiant heat flux for different mixing ratios regarding each equivalent ratio, 0.5, 0.6, and 0.7 , considering Silicon carbide 10 and 20 ppi, and Zirconia 20 ppi.

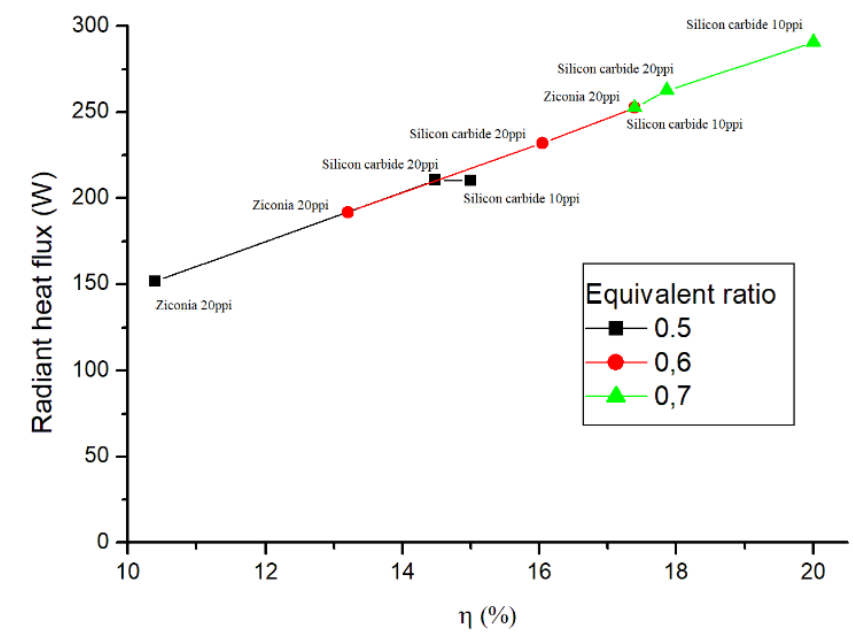

Figure 6. Radiant flux $\left(Q_{r}\right)$ in the function of mixing ratios for different equivalent ratios and materials composition

The results showed that the radiation emitted is higher as lower porosities, and that zirconia emission is lower than carbide silicon. The variation of the radiant flux with the measurement angle of direction of radiation emission, for the 10 ppi $\mathrm{SiC}$ matrix, can be seen in Figure 7.

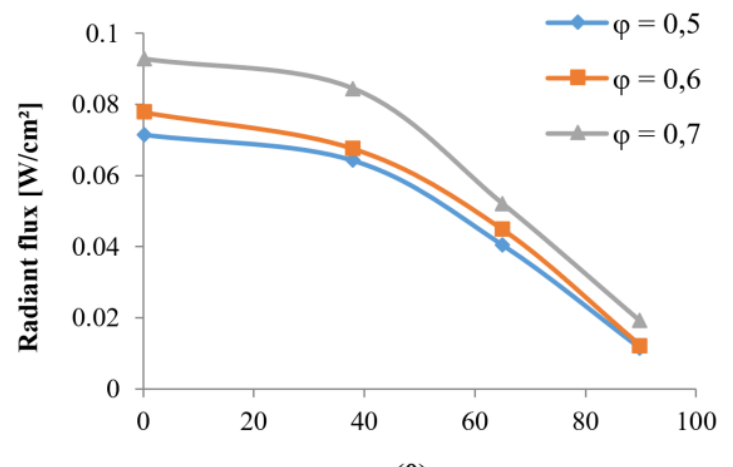

(日)

Figure 7. Radiant flux $\left(Q_{r}\right)$ by measurement angle $(\theta)$ for 10 ppi porosity silicon carbide

It can be seen that as the measurement angle increases (from vertical to a horizontal position), there is a decrease in the heat flux. This decay is also perceived for the other materials and porosities. Porous burners present a directional radiation emission, so decreasing the intensity with increasing angle is consistent. The radiation heat flux was higher for larger equivalence ratios, which also spread more energy for the surroundings. 


\section{CONCLUSIONS}

In this work, a workbench for radiant flow measurements for different materials and porosities was developed. Measurements were taken at different angles to map radiation behavior across the area of a half-sphere. The stabilization of the process proved to be a challenge because, for different riches, there is a flame speed range that must be respected. The measurements were valid only after reaching thermal equilibrium within the porous medium. The porosity of ceramic materials directly affects the radiation efficiency, so that the smaller the porosity, the higher the radiation efficiency, due to the presence of a larger area for heat exchange between the pores and a smaller loss by driving.

Regarding the materials, it was observed that silicon carbide has higher thermal efficiency than zirconia, an expected result, due to the higher emissivity and thermal conductivity of the material. However, $\mathrm{SiC}$ has a lower maximum operating temperature than the other compound, which is a disadvantage. Fact observed in the degradation of the 20 ppi silicon carbide ceramic filter in the equivalence ratio of 0.7 .

The radiant flux decay with the increase of the measurement angle was evaluated and is consistent with literature data, as well as the decrease of the radiation flux with the decrease of the linear density.

\section{REFERENCES}

[1] Vignoles, G.L. (2016). A hybrid random walk method for the simulation of coupled conduction and linearized radiation transfer at local scale in porous media with opaque solid phases. International Journal of Heat and Mass Transfer, 93: 707-719. https://doi.org/10.1016/j.ijheatmasstransfer.2015.10.056

[2] Ouarhlent, F., Soudani, A. (2019). Numerical study of the effect of permeability in a partially porous medium. Instrumentation Mesure Métrologie, 18(3): 243-248. https://doi.org/10.18280/i2m.180303

[3] Li, H., Lei, H., Chen, R. (2012). Preparation of porous $\mathrm{Fe}_{2} \mathrm{O}_{3} / \mathrm{SiO}_{2}$ nanocomposite abrasives and their chemical mechanical polishing behaviours on hard disk substrates. Thin Solid Films, 520(19): 6174-6178. https://doi.org/10.1016/j.tsf.2012.05.088

[4] Falsafi, I., Nemati, H. (2019). Numerical investigation of a low speed reacting flow behaviour in a porous duct. Aerospace Science and Technology, 93: 105304. https://doi.org/10.1016/j.ast.2019.105304

[5] Mahmoudi, Y. (2014). Effect of thermal radiation on temperature differential in a porous medium under local thermal non-equilibrium condition. International Journal of Heat and Mass Transfer, 76: 105-121. https://doi.org/10.1016/j.ijheatmasstransfer.2014.04.024

[6] Rajakumar K.V.B., Balamurugan K.S., Umasankara Reddy M., Ramana Murthy C.V. (2018). Radiation, dissipation and Dufour effects on MHD free convection Casson fluid flow through a vertical oscillatory porous plate with ion-slip current. International Journal of Heat and Technology, 36(2): 494-508 https://doi.org/10.18280/ijht.360214

[7] Ghalambaz, M., Sabour, M., Pop, I. (2016). Free convection in a square cavity filled by a porous medium saturated by a nanofluid: Viscous dissipation and radiation effects. Engineering Science and Technology, an International Journal, 19(3): 1244-1253. https://doi.org/10.1016/j.jestch.2016.02.006

[8] Caetano, N.R, Soares, D., Nunes, R.P., Pereira, F.M., Schneider, P.S., Vielmo, H.A., van der Laan, F.T. (2015). A comparison of experimental results of soot production in laminar premixed flames. Open Engineering, 5(1): 213-219. http://dx.doi.org/10.1515/eng-2015-0016

[9] Cataluña, R., Shah, Z., Venturi, V., Caetano, N.R., Da Silva, B.P., Azevedo, C.M.N., Da Silva, R., Suarez, P.A.Z., Oliveira, L.P. (2018). Production process of diamyl ether and its use as an additive in the formulation of aviation fuels. Fuel, 228: 226-233. http://dx.doi.org/10.1016/j.fuel.2018.04.167

[10] Nasser I., Duwairi H.M. (2016). Thermal dispersion effects on convection heat transfer in porous media with viscous dissipation. International Journal of Heat and Technology, 34(2): http://doi.org/10.18280/ijht.340208

[11] Sgard, F.C., Olny, X., Atalla, N., Castel, F. (2005). On the use of perforations to improve the sound absorption of porous materials. Applied Acoustics, 66(6): 625-651. https://doi.org/10.1016/j.apacoust.2004.09.008

[12] Caetano, N.R., Cataluña, R., Vielmo, H.A. (2015). Analysis of the effect on the mechanical injection engine using doped diesel fuel by ethanol and bio-oil. International Review of Mechanical Engineering, 9(2): 124-128. http://dx.doi.org/10.15866/ireme.v9i2.4341

[13] Cataluña, R., Shah, Z., Pelisson, L., Caetano, N.R., Da Silva, R., Azevedo, C. (2017). Biodiesel glycerides from the soybean ethylic route incomplete conversion on the diesel engines combustion process. Journal of the Brazilian Chemical Society, 1-8. http://dx.doi.org/10.21577/0103-5053.20170100

[14] Zhdanok, S.A., Dobrego, K.V., Futko, S.I. (2000). Effect of porous media transparency on spherical and cylindrical filtrational combustion heaters performance. International Journal of Heat and Mass Transfer, 43(18): 3469-3480. $\quad$ http://dx.doi.org/10.1016/S00179310(99)00320-8

[15] Cravero, C., Domenico, D., Leutcha, P.J., Marsano, D (2019). Strategies for the numerical modelling of regenerative pre-heating systems for recycled glass raw material. Mathematical Modelling of Engineering Problems, 6(3): 324-332. http://dx.doi.org/10.18280/mmep.060302

[16] Kumar, P.V., Ibrahim, S.M., Lorenzini G. (2017). Impact of thermal radiation and Joule heating on MHD mixed convection flow of a Jeffrey fluid over a stretching sheet using homotopy analysis method. International Journal of Heat and Technology, 35(4): 978-986. https://doi.org/10.18280/ijht.350434

[17] Klunk, M.A., Shah, Z., Caetano, N.R., Conceição, R. V., Wander, P.R., Dasgupta, S., Das, M. (2019). $\mathrm{CO}_{2}$ sequestration by magnesite mineralization through interaction between $\mathrm{Mg}$-brine and $\mathrm{CO}_{2}$ : Integrated laboratory experiments and computerized geochemical modelling. International Journal of Environmental Studies, $1-18$. https://doi.org/10.1080/00207233.2019.1675295

[18] Klunk, M.A., Dasgupta, S., Das, M., Wander, P.R. (2019). Computer codes of geochemical modeling used to water-rock interaction simple and complex systems. Periódico Tchê Química, 16(32): 108-118.

[19] Caetano, N.R., Venturini, M.S., Centeno, F.R., 
Lemmertz, C.K., Kyprianidis, K.G. (2018). Assessment of mathematical models for prediction of thermal radiation heat loss from laminar and turbulent jet nonpremixed flames. Thermal Science and Engineering Progress, 7: 241-247.

https://doi.org/10.1016/j.tsep.2018.06.008

[20] Zhang, R., Zhang, F., Feng, J., Qian, Y. (2014). Green and facile synthesis of porous $\mathrm{ZnCO}_{3}$ as a novel anode material for advanced lithium-ion batteries. Materials Letters, $\quad 118$ : 5-7. http://dx.doi.org/10.1016/j.matlet.2013.12.028

[21] De Lemos, M.J.S. (2009). Numerical simulation of turbulent combustion in porous materials. International Communications in Heat and Mass Transfer, 36(10): 996-1001.

https://doi.org/10.1016/j.icheatmasstransfer.2009.07.00 6

[22] Usman, H., Mabood, F., Lorenzini, G. (2016). Heat and mass transfer along vertical channel in porous medium with radiation effect and slip condition. International Journal of Heat and Technology, 34(1): 129-136. http://dx.doi.org/10.18280/ijht.340119

[23] Jugjai, S., Wongpanit, N., Laoketkan, T., Nokkaew, S. (2002). The combustion of liquid fuels using a porous medium. Experimental Thermal and Fluid Science, 26(1): 15-23. http://dx.doi.org/10.1016/S0894-1777(02)001061

[24] Klunk, M.A., Das, M., Dasgupta, S., Impiombato, A.N., Caetano, N.C., Wander, P.R., Moraes, C.A.M. (2020). Comparative study using different external sources of aluminum on the zeolites synthesis from rice husk ash. Materials Research Express, 7(1): 015023. http://dx.doi.org/10.1088/2053-1591/ab608d

[25] Yang, Z., Sun, Y., Cui, J., Yang, Z., Guan, T. (2018). A three-scale homogenization algorithm for coupled conduction-radiation problems in porous materials with multiple configurations. International Journal of Heat and Mass Transfer, 125: 1196-1211. http://dx.doi.org/10.1016/j.ijheatmasstransfer.2018.05.0 24

[26] Ruoso, F.S., Bittencourt, L.C., Sudati, L.U., Klunk, M.A., Caetano, N.R. (2019). New parameters for the forest biomass waste ecofirewood manufacturing process optimization. Periódico Tchê Química, 16(32): 560-571.

[27] Trifirò, F. (2019). Fuels from Biomass. TECNICA ITALIANA-Italian Journal of Engineering Science, 63(1): 86-93. http://dx.doi.org/10.18280/ti-ijes.630112

[28] Kaewchart, K., Krittacom, B. (2017). Comparison of combustion behaviour between solid porous burners installed the porous emitter and non-porous emitter. Energy Procedia, 138: 2-7. https://doi.org/10.1016/j.egypro.2017.10.035

[29] Mahmoud, A., Mejri, I. (2015). Analysis of conductionradiation heat transfer with variable thermal conductivity and variable refractive index: Application of the lattice Boltzmann method. International Journal of Heat and Mass $\quad$ Transfer, $33(1)$ : $1-8$. http://dx.doi.org/10.18280/ijht.330101

[30] Miguel, A.F., Silva, A.M. (2000). Porous materials to control climate behaviour of enclosures: an application to the study of screened greenhouses. Energy and Buildings, $\quad 31(3)$ : 195-209. http://dx.doi.org/10.1016/S0378-7788(99)00010-9

[31] Fraga, A., Klunk, M.A., Oliveira, A., Furtado, G.,
Knornschild, G.H., Dick, L.F.P. (2014). Soil corrosion of the AISI1020 steel buried near electrical power transmission line towers. Materials Research, 17: 16371643. http://dx.doi.org/10.1590/1516-1439.305714

[32] Dey, D., Deb, H.R. (2008). Hydromagnetic flow of power law fluid in a porous medium with energy dissipation: A numerical approach. TECNICA ITALIANA-Italian Journal of Engineering Science, 61(2): $\quad 130-134 . \quad \mathrm{http}: / / \mathrm{dx}$. doi.org/10.18280/tiijes.620211

[33] Caetano, N.R., Stapasolla, T.Z., Peng, F.B., Schneider, P.S., Pereira, F.M., Vielmo, H.A. (2015). Diffusion flame stability of low calorific fuels. Defect and Diffusion $\quad$ Forum, 362: 29-37. http://dx.doi.org/10.4028/www.scientific.net/DDF.362. 29

[34] Caetano, N.R., Silva, B.P. (2017). Technical and economic viability for the briquettes manufacture. Defect and Diffusion Forum, 380: 218-226. https://doi.org/10.4028/www.scientific.net/DDF.380.21 8

[35] Hunt, G., Torabi, M., Govone, L., Karimi, N., Mehdizadeh, A. (2018). Two-dimensional heat and mass transfer and thermodynamic analyses of porous microreactors with Soret and thermal radiation effectsAn analytical approach. Chemical Engineering and Processing - Process Intensification, 126: 190-205. https://doi.org/10.1016/j.cep.2018.02.025

[36] Rousseau, B., De Sousa, M.D., Echegut, P., Thovert, J-F. (2011). Textural parameters influencing the radiative properties of a semitransparent porous media. International Journal of Thermal Sciences, 50(2): 178186.

http://dx.doi.org/10.1016/j.ijthermalsci.2010.10.001

[37] Bounazef, M., Djeffal, A., Serier, M., Bedia, E.A.A. (2009). Optimisation by behaviour modelling of a protective porous material. Computational Materials Science, $44(3)$ : 921-928. http://dx.doi.org/10.1016/j.commatsci.2008.06.022

[38] Klunk, M.A., Shah, Z., Wander, P.R. (2019). Use of montmorillonite clay for adsorption malachite green dye. Periódico Tchê Química, 16(32): 279-286.

[39] Hosseini, S.A., Sadrnezhaad, S.K., Ekrami, A. (2009). Phase transformation behaviour of porous NiTi alloy fabricated by powder metallurgical method. Materials Science and Engineering: C, 29(7): 2203-2207. https://doi.org/10.1016/j.msec.2009.05.006

[40] Adesanya, S.O., Fakoya, M.B., Falade, J.A., Lebelo, R. S., Okewole, D.M. (2017). Existence of secondary flows in a reactive viscous fluid through a channel filled with a porous medium. International Journal of Heat and Mass Transfer, 35(2): 262-266. http://dx.doi.org/10.18280/ijht.350205

[41] Park, B.H., Oh, S.C., Hur, J.M. (2014). Measurement of $\mathrm{LiCl}$ removal behaviour from porous solids by vacuum evaporation. Vacuum, 109: 61-67. https://doi.org/10.1016/j.vacuum.2014.06.011

[42] Wang, L.M., Chen, J., Ewing, R.C. (2004). Radiation and thermal effects on porous and layer structured materials as getters of radionuclides. Current Opinion in Solid State and Materials Science, 8(6): 405-418. https://doi.org/10.1016/j.cossms.2005.04.002

[43] Saneinejad, S., Moonen, P., Carmeliet, J. (2014). Coupled CFD, radiation and porous media model for 
evaluating the micro-climate in an urban environment. Journal of Wind Engineering and Industrial Aerodynamics, 128: 1-11. https://doi.org/10.1016/j.jweia.2014.02.005

[44] Wang, C., Feng, L., Li, W., Zheng, J., Tian, W., Li, X (2012). Shape-stabilized phase change materials based on polyethylene glycol/porous carbon composite: The influence of the pore structure of the carbon materials. Solar Energy Materials and Solar Cells, 105: 21-26. https://doi.org/10.1016/j.solmat.2012.05.031

[45] Gross, U., Tran, L.T.S. (2004). Radiation effects on transient hot-wire measurements in absorbing and emitting porous media. International Journal of Heat and Mass Transfer, 47(14-16): 3279-3290. https://doi.org/10.1016/j.ijheatmasstransfer.2004.02.014

[46] Chen, Z.Q., Shi, M.H. (2005). Study of heat and moisture migration properties in porous building materials Applied Thermal Engineering, 25(1): 61-71. https://doi.org/10.1016/j.applthermaleng.2004.05.001

[47] Gandjalikhan Nassab, S.A., Maramisaran, M. (2009). Transient numerical analysis of a multi-layered porous heat exchanger including gas radiation effects. International Journal of Thermal Sciences, 48(8): 15861595. https://doi.org/10.1016/j.ijthermalsci.2008.12.014

[48] Badruddin, I.A., Zainal, Z.A., Narayana, P.A.A., Seetharamu, K.N. (2007). Numerical analysis of convection conduction and radiation using a nonequilibrium model in a square porous cavity. International Journal of Thermal Sciences, 46(1): 20-29. https://doi.org/10.1016/j.ijthermalsci.2006.03.006

[49] Wang, S.C., Chen, C.K., Yang, Y.T. (2002). Natural convection of non-Newtonian fluids through permeable axisymmetric and two-dimensional bodies in a porous medium. International Journal of Heat and Mass Transfer, 45(2): $\quad 393-408 . \quad$ https://doi.org/10.1016/S00179310(01)00123-5

[50] Mital, R., Gore, J.P., Visakanta, R. (1997). A study of the structure of submerged reaction zone in porous ceramic radiant burners. Combustion and Flame, 111: 175-184. https://doi.org/10.1016/S0010-2180(97)00006-0

[51] Yang, Z., Cui, J., Sun, Y., Liu, Y., Xiao, Y. (2017). A stochastic multiscale method for thermo-mechanical analysis arising from random porous materials with interior surface radiation. Advances in Engineering Software, 104

$12-27$ https://doi.org/10.1016/j.advengsoft.2016.11.006

[52] Deng, Z., Zhan, Y., Duan, H., Xiong, Z., Bai, F., Wang, Y. (2002). Optical microcavity based on porous and organic materials. Synthetic Metals, 129(3): 299-302. https://doi.org/10.1016/S0379-6779(02)00100-5

[53] Chen, X., Sutton, W.H. (2005). Enhancement of heat transfer: Combined convection and radiation in the entrance region of circular ducts with porous inserts. International Journal of Heat and Mass Transfer, 48(2526):

$5460-5474$ https://doi.org/10.1016/j.ijheatmasstransfer.2005.06.025

[54] Saad, A.P, Abdul, Rahim, R.A., Harun, M.N., Basri, H., Abdullah, J., Abdul Kadir, M.R., Syahrom, A. (2017) The influence of flow rates on the dynamic degradation behaviour of porous magnesium under a simulated environment of human cancellous bone. Materials \& Design, $\quad 122$ : 268-279. https://doi.org/10.1016/j.matdes.2017.03.029

[55] Lee, S.Y., Park, S.J. (2011). Preparation and characterization of ordered porous carbons for increasing hydrogen storage behaviours. Journal of Solid State Chemistry, $184(10)$ : 2655-2660. https://doi.org/10.1016/j.jssc.2011.07.034

[56] Bouma, P.H., De Goey, L.P.H. (1999). Premixed combustion on ceramic foan burners. Combustion and Flame, 119: 133-143. https://doi.org/10.1016/S00102180(99)00050-4

[57] Belver, C., Bañares, M.A., Vicente, M.A. (2002). Preparation of porous silica by acid activation of metakaolins. Studies in Surface Science and Catalysis, 307-314. https://doi.org/10.1016/S0167-2991(02)801495

[58] Fend, T., Hoffschmidt, B., Pitz-Paal, R., Reutter, O., Rietbrock, P. (2004). Porous materials as open volumetric solar receivers: Experimental determination of thermophysical and heat transfer properties. Energy, 29(5-6): 823-833. https://doi.org/10.1016/S03605442(03)00188-9

[59] Zhang, L., Li, X., Wang, S., Romito, K.G., Huang, K. (2011). High conductivity mixed oxide-ion and carbonate-ion conductors supported by a prefabricated porous solid-oxide matrix. Electrochemistry Communications, 13(6): 554-557. https://doi.org/10.1016/j.elecom.2011.03.008

[60] Kaviany, M. (2012). Principles of Heat Transfer in Porous Media, Springer Science \& Business Media. Springer, New York, NY.

[61] Beji, L., Bouzaïene, L., Ismaïl, B., Sfaxi, L., Maaref, H., Ben Ouada, H. (2005). Long-wavelength emission from single InAs quantum dots layer grown on porous GaAs substrate. Microelectronics Journal, 36(2): 99-103. https://doi.org/10.1016/j.mejo.2004.11.003

[62] Chamard, V., Setzu, S., Romestain, R. (2002). Light assisted formation of porous silicon investigated by $\mathrm{X}$ ray diffraction and reflectivity. Applied Surface Science, 191(1-4): 319-327. https://doi.org/10.1016/S01694332(02)00256-8

[63] Hsu, P., Evans. W.D., Howell. J.R. (1993). Experimental and numerical study of premixed combustion within nonhomegeneous porous ceramics. Combustion Science and Technology, 90: 149-172. https://doi.org/10.1080/00102209308907608

[64] Itoh, Y., Ueda, K. (2004). Hydrogen and oxygen behaviours on Porous-Si surfaces observed using a scanning ESD ion microscope. Applied Surface Science, 237(1-4): https://doi.org/10.1016/j.apsusc.2004.06.146

[65] Badruddin, I.A., Zainal, Z.A., Khan, Z.A., Mallick, Z. (2007). Effect of viscous dissipation and radiation on natural convection in a porous medium embedded within vertical annulus. International Journal of Thermal Sciences, $46(3)$ : 221-227. https://doi.org/10.1016/j.ijthermalsci.2006.05.005

[66] Tang, C., Zhang, Q., Wang, K., Fu, Q., Zhang, C. (2009). Water transport behaviour of chitosan porous membranes containing multi-walled carbon nanotubes (MWNTs). Journal of Membrane Science, 337(1-2): 240-247. https://doi.org/10.1016/j.memsci.2009.03.048

[67] Hamila, R., Chaabane, R., Askri, F., Jemni, A., Nasrallah, S.B. (2017). Lattice Boltzmann method for heat transfer problems with variable thermal conductivity. International Journal of Heat and Technology, 35(2): 313-324. http://dx.doi.org/10.18280/ijht.350212 
[68] Kim, S.G., Yoon, S.P., Han, J., Nam, S.W., Lim, T.H., Oh, I.H., Hong, S.A. (2002). Mechanical strength of porous nickel plates containing lithium and their performance as the cathode for MCFC. Journal of Power Sources, 110(1): 80-85. https://doi.org/10.1016/S0378-
7753(02)00235-5

[69] Mandal, S., Müller, A.H.E. (2008). Facile route to the synthesis of porous $\alpha-\mathrm{Fe}_{2} \mathrm{O}_{3}$ nanorods. Materials Chemistry and Physics, 111(2-3): 438-443. https://doi.org/10.1016/j.matchemphys.2008.04.043 